\title{
Article \\ Detection and Drug Susceptibility Testing of Neisseria gonorrhoeae Using Isothermal Microcalorimetry
}

\author{
Anabel E. Grütter ${ }^{1,+}$, Tecla Lafranca ${ }^{1,+}$, Aurelia Pahnita Sigg ${ }^{1}$, Max Mariotti ${ }^{1}$, Gernot Bonkat ${ }^{2}$ \\ and Olivier Braissant ${ }^{1, *}$ \\ 1 Department of Biomedical Engineering, University of Basel, Gewerbestrasse 14, 4123 Allschwil, Switzerland; \\ anabel.gruetter@stud.unibas.ch (A.E.G.); tecla.lafranca@stud.unibas.ch (T.L.); \\ aureliapahnita.sigg@stud.unibas.ch (A.P.S.); max.mariotti@stud.unibas.ch (M.M.) \\ 2 alta uro AG, Centralbahnplatz 6, 4051 Basel, Switzerland; Bonkat@alta-uro.com \\ * Correspondence: olivier.braissant@unibas.ch \\ + These authors contributed equally to this publication.
}

Citation: Grütter, A.E.; Lafranca, T.; Sigg, A.P.; Mariotti, M.; Bonkat, G.; Braissant, O. Detection and Drug Susceptibility Testing of Neisseria gonorrhoeae Using Isothermal Microcalorimetry. Microorganisms 2021, 9, 2337. https://doi.org/ 10.3390/microorganisms 9112337

Academic Editor: Karim Fahmy

Received: 20 September 2021

Accepted: 8 November 2021

Published: 11 November 2021

Publisher's Note: MDPI stays neutral with regard to jurisdictional claims in published maps and institutional affiliations.

Copyright: (c) 2021 by the authors. Licensee MDPI, Basel, Switzerland. This article is an open access article distributed under the terms and conditions of the Creative Commons Attribution (CC BY) license (https:/ / creativecommons.org/licenses/by/ $4.0 /)$.

\begin{abstract}
Background: Gonorrhea is a frequently encountered sexually transmitted disease that results in urethritis and can further lead to pelvic inflammatory disease, infertility, and possibly disseminated gonococcal infections. Thus, it must be diagnosed promptly and accurately. In addition, drug susceptibility testing should be performed rapidly as well. Unfortunately, Neisseria gonorrhoea is a fastidious microorganism that is difficult to grow and requires culturing in an opaque medium. Methods: Here, we used isothermal microcalorimetry (IMC) to monitor the growth and the antimicrobial susceptibility of $N$. gonorrhoea. Results: Using IMC, concentrations of $N$. gonorrhoea between 2000 and $1 \mathrm{CFU} \cdot \mathrm{mL}^{-1}$ were detected within 12 to $33 \mathrm{~h}$. In addition, drug susceptibility could be monitored easily. Conclusions: The use of isothermal microcalorimetry provides an interesting and useful tool to detect and characterize fastidious microbes such as $N$. gonorrhoea that require media incompatible with optical detection conventionally used in many commercial systems.
\end{abstract}

Keywords: isothermal microcalorimetry; Neisseria gonorrhoea; antimicrobials

\section{Introduction}

Gonorrhea is the second most common bacterial sexually transmitted disease (STI) worldwide. According to the World Health Organization (WHO), there were around 87 million new infections in 2016 [1,2]. The causative pathogen of Gonorrhea, Neisseria gonorrhoea $(\mathrm{Ng})$, is a Gram-negative diplococcus that infects the urogenital tract as well as the rectum and the pharynx [3-5]. Men with such a urogenital infection are often symptomatic, presented as urethritis [3,4]. On the contrary, most women are asymptomatic. Symptoms (if any) include urethritis or cervicitis and are often non-specific. Rectal and pharyngeal Gonorrhea are present in both genders and remain mostly asymptomatic [4,6,7]. Due often non-specific symptoms or even asymptomatic disease progressions, Gonorrhea can extend into an ascending infection. Complications include pelvic inflammatory disease (PID), ectopic pregnancy, infertility and possibly disseminated gonococcal infections (DGIs) [8,9]. Unfortunately, because many patients remain asymptomatic and the increase in sexually risky behavior, the incidence continues to rise.

Furthermore, the time and effort required for the detection of $N$. gonorrhoea and the determination of its antimicrobial susceptibility are high. For these reasons, an empirical antimicrobial therapy is often chosen as first-line treatment. This treatment consists of a single dose of ceftriaxone in combination with azithromycin (see details in EAU guidelines [10]). As with other bacteria, N. gonorrhoea is also able to develop resistance to various antibiotics, including the first-line ones and many others [11]. Due to the emergence of resistance and the consequent ineffectiveness of the antibiotics used, antibacterial susceptibility testing becomes crucial to ensure effective and targeted therapy. Minimizing inadequate treatment 
also reduces the emergence of new resistance [12]. Because of the growing number of cases, the inefficiency of the currently applied diagnostic methods and the emergence of new resistant strains, diagnostic methods that allow faster and targeted treatment are urgently needed.

Currently, diagnosis of $N$. gonorrhoea relies mostly on a urethral swab followed by microscopy, microbial culture or nucleic acid amplification test (NAAT) such as PCR or LAMP. In high income settings the nucleic acid amplification test (NAAT) is the most used test to diagnose Gonorrhea, whereas it is rarely used in low-income settings, due to the high associated costs [13-15]. NAAT has a high specificity and sensitivity both in urethral gonococcal infections and extragenital gonococcal infections. However, it is recommended that a positive test result from an extragenital infection should be confirmed with an alternative method due to the possibility of cross reactivity with commensal or atypical Neisseria species [16-19]. In addition, NAAT may be superior to culture in some respects, for example in sensitivity, ease, and speed of performance, as shown in many studies. However, it lacks the possibility of direct antimicrobial susceptibility testing [20-22]. Therefore, there is still the need for a new method, which can both detect Neisseria and allows determination of antimicrobial resistance pattern in an easy and practical manner.

In this context, we investigated the use of isothermal microcalorimetry (IMC) for the detection and antimicrobial susceptibility testing of N. gonorrhoea. For microbiologists, $N$. gonorrhoea is considered to be a fastidious microorganism that requires specific growth medium (such as chocolate agar, GC medium) that are solid and/or opaque due to the presence of components such as agar (to make the medium solid), starch and hemoglobin (making the medium cloudy or even opaque). Isothermal microcalorimetry measures metabolic heat produced by active or replicating microorganisms in a given medium $[23,24]$. Isothermal microcalorimetry (IMC) is a laboratory method for the measurement and recording of real-time heat production rate (heatflow) at microwatt levels $(\mu \mathrm{J} / \mathrm{sec}=\mu \mathrm{W})$ during bacterial growth (i.e., heatflow curve) [25-28]. As only heat is measured, IMC does not require a transparent or liquid medium, making it suitable for the detection of $N$. gonorrhoea in the medium. Previous studies have already shown promising results in this field. For example, in 2012 a study using IMC demonstrated that this method allows rapid detection of bacteriuria (in just $3.1 \mathrm{~h}$ ), enables the pathogen to be targeted through different heat flow patterns and that low colony counts $\left(10^{3} \mathrm{CFU} / \mathrm{mL}\right)$ are needed for the detection. Bacterial strains of the most common urinary tract pathogens were used in this study: Staphylococcus aureus, Enterococcus faecalis, Proteus mirabilis and Escherichia coli [28]. Braissant and colleagues demonstrated that IMC could be used to find an adequate antimicrobial therapy for urosepsis in just seven hours [29]. Regarding the drug susceptibility, isothermal microcalorimetry has already been used for various species such as MRSA [30], Aspergillus [31], Mycobacterium [32] and S. aureus and E. coli [33]. Finally, the use of solid and opaque medium has already been shown to be possible with IMC, especially in the context of tuberculosis diagnosis and drug susceptibility testing $[34,35]$. Given the reliability of these results, the aim of this study was to use this procedure in a field that to our knowledge has not yet been explored, namely antimicrobial susceptibility testing for N. gonorrhoea using IMC. Our aim was, therefore, to apply IMC to a bacterium that has not attracted much attention until now and to provide a sensitive, rapid and effective method of diagnosis and drug susceptibility testing that can ideally act as a means of point-of-care testing (POCT) in the clinical world.

\section{Materials and Methods}

\subsection{Organisms}

The strains of N. gonorrhoea (ATCC 19424 and ATCC 43069) were obtained as dehydrated pellets (Microbiologics, St Cloud, MN, USA) and stored at $4{ }^{\circ} \mathrm{C}$ before use. The pellets were rehydrated in sterile brain-heart infusion (BHI) medium previously autoclaved at $121{ }^{\circ} \mathrm{C}$ for $15 \mathrm{~min}$ according to the manufacturer's instructions. The pellets were 
rehydrated $1 \mathrm{~h}$ before use. Pellets where homogenized using a grinding tool and through repeated vortexing. Following homogenization, the solution was used as inoculum for the different experiments described below. In addition, the inoculum bacterial concentration was determined by plating on Columbia agar with added $5 \%$ sheep blood (Becton Dickinson (BD), Franklin Lakes, NJ, USA) after serial 10-fold dilutions. An additional plate was prepared by streaking $10 \mu \mathrm{L}$ of the undiluted inoculum on the same medium. All plates were incubated $48 \mathrm{~h}$ at $37^{\circ} \mathrm{C}$ and visually inspected or counted after this time.

\subsection{Detection in Various Medium}

To test the effects of different supplement addition on the growth and thus further detection in urine or medium, supplements were added to the urine or the GC base medium (Condalab, Madrid, Spain) according to Table 1. GC medium base and hemoglobin solution were autoclaved separately at $121^{\circ} \mathrm{C}$ for $15 \mathrm{~min}$ and mixed after cooling down. All other components were obtained sterile and added aseptically to obtain the final medium. Urine was obtained from voluntary healthy donors and was rapidly centrifuged to remove sediments (if any). A final filtration through a $0.2 \mu \mathrm{m}$ filter (stericup) was performed to ensure sterility and clarity. After filtration, the sterile urine was used directly or stored at $4{ }^{\circ} \mathrm{C}$ until use if required. All additions to urine were made aseptically.

Table 1. Medium composition tested to measure growth parameters of $N$. gonorrhoea and define the best possible liquid medium.

\begin{tabular}{ccccc}
\hline No Supplement & Urine & $\begin{array}{c}\text { Urine }+ \\
\text { Hemoglobin (1\% w/v) }\end{array}$ & GC Medium & $\begin{array}{c}\text { GC Medium + } \\
\text { Hemoglobin (1\% w/v) }\end{array}$ \\
\hline Isovitale X & $1 \% v / v$ & $1 \% v / v$ & $1 \% v / v$ & $1 \% v / v{ }^{*}$ \\
\hline Sheep blood ** & $1 \% v / v$ & $1 \% v / v$ & $1 \% v / v$ & $1 \% v / v$ \\
\hline * denotes the composition of the ATCC 814 medium. ** defibrinated. &
\end{tabular}

In addition, using the medium providing the best growth (i.e., ATCC 814 medium-see results section for details) we also performed a dilution series to determine the detection speed. Detection was considered positive when the signal passed above a threshold of $10 \mu \mathrm{W}$.

\subsection{Drug Susceptibility Testing}

Measurements performed in the previous section showed that GC medium (ATCC medium no. 814$)$ containing hemoglobin $(1 \% w / v)$ and Isovitale $X(1 \% v / v)$ was the most effective medium for the cultivation of the $N$. gonorrhoea strains used (see results section for details). We therefore determined the drug susceptibility in this medium. For this proof of principle, we used ceftriaxone at the following concentrations: $4.17,1.25,0.42,0.13$ and $0.04 \mu \mathrm{g} \cdot \mathrm{L}^{-1}$. Sterile controls and controls without antimicrobials were subjected to the same conditions.

\subsection{Calorimetry Procedure}

All the samples were prepared in sterile $4 \mathrm{~mL}$ calorimetric glass ampoules. Then, $3 \mathrm{~mL}$ of sample was placed in the ampoule, and the ampoule was sealed. The ampoule was introduced into the calorimeter (TAM III, Waters/TA, New Castle, DE, USA) following the two-step thermal equilibration procedure recommended by the manufacturer. After $1 \mathrm{~h}$ of thermal equilibration, heat production rates (heatflow) were recorded until they returned to baseline or for at least $96 \mathrm{~h}$. At the end of the experiment, data were resampled to obtain an effective sampling rate of 1 data point every $5 \mathrm{~min}$ and exported as a CSV file.

\subsection{Statistical Analysis}

All the calculations were performed in the statistics program R. The raw data (i.e., heatflow curves) were integrated to obtain heat over time curves. All further curve fitting was performed under the assumption that the heat produced during growth is proportional to the 
growth curve (i.e., that the cost of producing a bacterial cell remains constant) [36,37], and using the Gompertz growth model the maximal growth rate $(\mu)$, the lag phase $(\lambda)$, and the maximum heat $\left(Q_{\max }\right)$ were calculated from the heat over time curve [37-39]. Additionally, heatflow above $10 \mu \mathrm{W}$ was considered to be the threshold for positive detection, and the corresponding time was recorded.

\section{Results}

\subsection{Effect of Medium and Supplements}

N. gonorrhoea ATCC 19424 was used to test for different growth in the different media. The results are summarized in Table 2. This strain of N. gonorrhoea was not cultivable in any urine-based medium. We assume that the concentration of necessary nutrients is too low even with morning urine. This means the detection of $N$. gonorrhoea with IMC in urine or artificial urine is compromised. However, using GC-based medium showed growth in all conditions. The growth was improved by the addition of Isovitale $\mathrm{X}$ supplement and hemoglobin to a lesser extent. The use of sheep blood did not improve growth and even showed a decrease (however, the decrease was not significant). Out of the used mediums and additions, the conventional growth medium (GC medium, ATCC medium no. 814) with hemoglobin and Isovitale $X$ supplement performed the best since it showed the highest growth rate with a low lag phase compared to the other combinations. In this medium the growth pattern shows a main peak with additional smaller peaks that are found before the maximum activity is reached (see Figure 1). A possible explanation for the multiple peaks could be the use of different nutrients or terminal electron acceptors by $N$. gonorrhoea during its growth as previously described $[24,27,40]$.

Table 2. Growth parameters of N. gonorrhoea in the different media used. The results are the mean of four replicates and the associated standard deviation.

\begin{tabular}{|c|c|c|c|c|}
\hline Growth Medium & $\begin{array}{l}\text { Growth Rate } \\
\left(\mathbf{h}^{-1}\right)\end{array}$ & $\begin{array}{l}\text { Lag Phase } \\
\text { (h) }\end{array}$ & $\begin{array}{l}\text { Total Heat } \\
\text { (J) }\end{array}$ & $\begin{array}{l}\text { TTP } \\
\text { (h) }\end{array}$ \\
\hline GC & $0.095 \pm 0.010$ & $39.4 \pm 16.2$ & $3.74 \pm 1.30$ & $67.5 \pm 10.7$ \\
\hline GC + Isovitale X & $0.307 \pm 0.015$ & $28.8 \pm 1.8$ & $4.83 \pm 0.38$ & $40.8 \pm 0.8$ \\
\hline GC + Isovitale X + Blood & $0.234 \pm 0.025$ & $19.6 \pm 1.3$ & $5.34 \pm 0.14$ & $39.6 \pm 3.6$ \\
\hline GC + hemoglobin & $0.119 \pm 0.016$ & $16.7 \pm 1.2$ & $4.65 \pm 0.17$ & $36.2 \pm 5.2$ \\
\hline GC + hemoglobin + Isovitale X & $0.322 \pm 0.025$ & $17.3 \pm 0.7$ & $5.26 \pm 0.12$ & $29.4 \pm 1.0$ \\
\hline GC + hemoglobin + Isovitale X + blood & $0.305 \pm 0.016$ & $19.3 \pm 1.0$ & $5.47 \pm 0.08$ & $28.9 \pm 2.4$ \\
\hline Sterile GC medium & $0.002 \pm 0.001$ & ND & $0.12 \pm 0.05$ & ND \\
\hline Urine & $0.007 \pm 0.001$ & ND & $0.28 \pm 0.08$ & ND \\
\hline Urine + Isovitale $\mathrm{X}$ & $0.012 \pm 0.001$ & ND & $0.59 \pm 0.08$ & ND \\
\hline Urine + Isovitale $X+$ blood & $0.011 \pm 0.003$ & ND & $0.47 \pm 0.08$ & ND \\
\hline Urine + hemoglobin & $0.004 \pm 0.003$ & ND & $0.60 \pm 0.71$ & ND \\
\hline Urine + hemoglobin + Isovitale $X$ & $0.006 \pm 0.003$ & ND & $0.60 \pm 0.51$ & ND \\
\hline Urine + hemoglobin + Isovitale $X+$ blood & $0.004 \pm 0.001$ & ND & $0.36 \pm 0.06$ & ND \\
\hline Sterile filtered urine & $0.004 \pm 0.001$ & ND & $0.62 \pm 0.45$ & ND \\
\hline
\end{tabular}

\subsection{Time to Detection}

To determine the time to detection, we used a $10 \mu \mathrm{W}$ threshold corresponding to ca. $3.3 \cdot 10^{5} \mathrm{CFU} \cdot \mathrm{mL}^{-1}$ (assuming a $2 \mathrm{pW}$ per cell heat production rate $[41,42]$ ). The serial dilution with the two selected strains of $N$. gonorrhoea led to measured detection times between 12 and $33 \mathrm{~h}$ depending on the strain and bacterial concentration used (that were of rather low concentration but comparable to those found in patient urine- Table 3). Only one sample with very low CFU counts of the ATCC 43069 strain did not pass the threshold of $10 \mu \mathrm{W}$ (although it came close). This emphasizes that the differences between the strains 
of the same organism should be taken into account. In addition, we assume that it is likely that after sedimentation of the medium, only a micro-colony could develop, being trapped in the sediment. Increasing growth would have probably required stirring or shaking that is not possible with the used instrument.
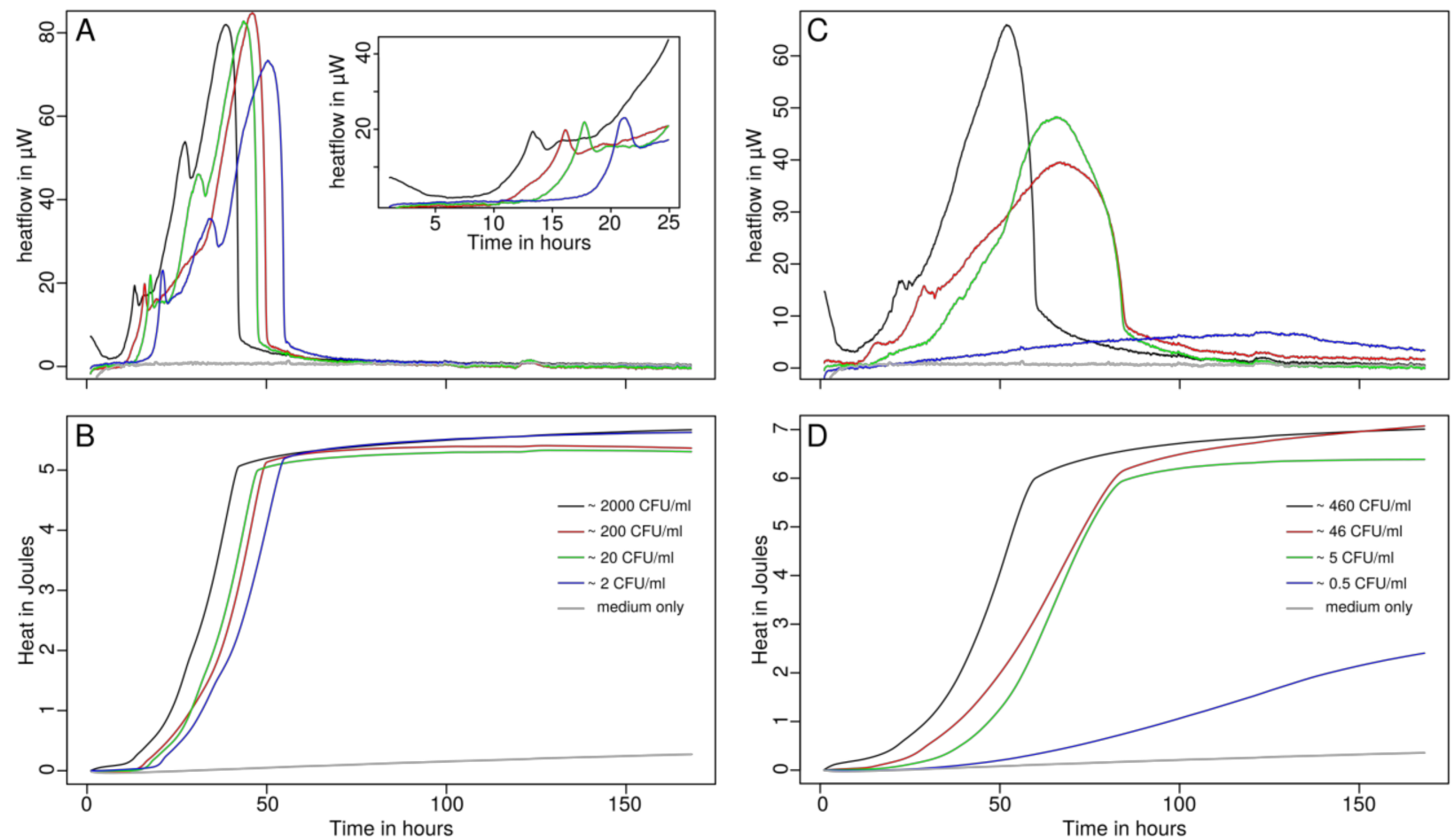

Figure 1. Growth of N. gonorrhoea ATCC 19424 (A,B) and ATCC 43069 (C,D) monitored using IMC. A: Heatflow of N. gonorrhoea ATCC 19424 and insert showing details of the initial 25 h. B: Heat produced by of N. gonorrhoea ATCC 19424 over time showing a curve similar to a growth curve. C: Heatflow of N. gonorrhoea ATCC 19424. D: Heat produced by of N. gonorrhoea ATCC 19424 over time showing a curve similar to a growth curve.

Table 3. Table showing the detection time with respect to the number of cells in the medium. The threshold for positive detection was set at $10 \mu \mathrm{W}\left(10 \mu \mathrm{W}\right.$ is approximately $3.3 \times 10^{5} \mathrm{CFU} \cdot \mathrm{mL}^{-1}$; see main text).

\begin{tabular}{cccc}
\hline \multicolumn{2}{c}{ ATCC 19424 } & \multicolumn{2}{c}{ ATCC 43069 } \\
\hline CFU $\mathbf{m L}^{-1}$ & $\begin{array}{c}\text { Time to } \\
\text { Detection (h) }\end{array}$ & CFU $\cdot \mathbf{m L}^{-1}$ & $\begin{array}{c}\text { Time to } \\
\text { Detection (h) }\end{array}$ \\
\hline$\sim 2400$ & $12.0 \pm 0.3$ & $\sim 460$ & $18.9 \pm 0.4$ \\
\hline$\sim 240$ & $14.6 \pm 0.2$ & $\sim 46$ & $26.0 \pm 0.4$ \\
\hline$\sim 24$ & $16.9 \pm 0.4$ & $\sim 5$ & $33.6 \pm 3.3$ \\
\hline$\sim 2$ & $21.9 \pm 3.2$ & $\sim 0.5 * *$ & ND * \\
\hline 0 & ND & 0 & ND \\
\hline Sterile controls & ND & Sterile controls & ND
\end{tabular}

* Growth was detected, but the signal did not reach the threshold of $10 \mu \mathrm{W} .{ }^{* *}$ At this concentration only one out of the three replicates showed growth. See figure for details.

\subsection{Drug Susceptibility Testing}

When increasing concentrations of ceftriaxone were added up to $3 \times \mathrm{MIC}$, inhibition of Neisseria growth was clearly visible (Figure 2). The growth rate decreased from 0.29 to $0.00 \mathrm{~h}^{-1}$ at MIC, as the lag phase duration remained roughly similar for all the samples between $29.9 \pm 1.5$ and $36.1 \pm 1.5$. The MIC measured for both strains is consistent with 
literature values for these well characterized susceptible strains. Please note that at MIC level the strain ATCC 19424 shows considerably delayed growth and was clearly visible (although very slow) only after $100 \mathrm{~h}$ (data not shown). This shows that the methodology previously developed for urosepsis using a single concentration of antimicrobial to rapidly determine if a strain is susceptible or resistant is also applicable with N. gonorrhoea. However, due to the slow growth and fastidious nature of Neisseria species, it is likely that at least 12 to $15 \mathrm{~h}$ could be needed for such a discrimination.
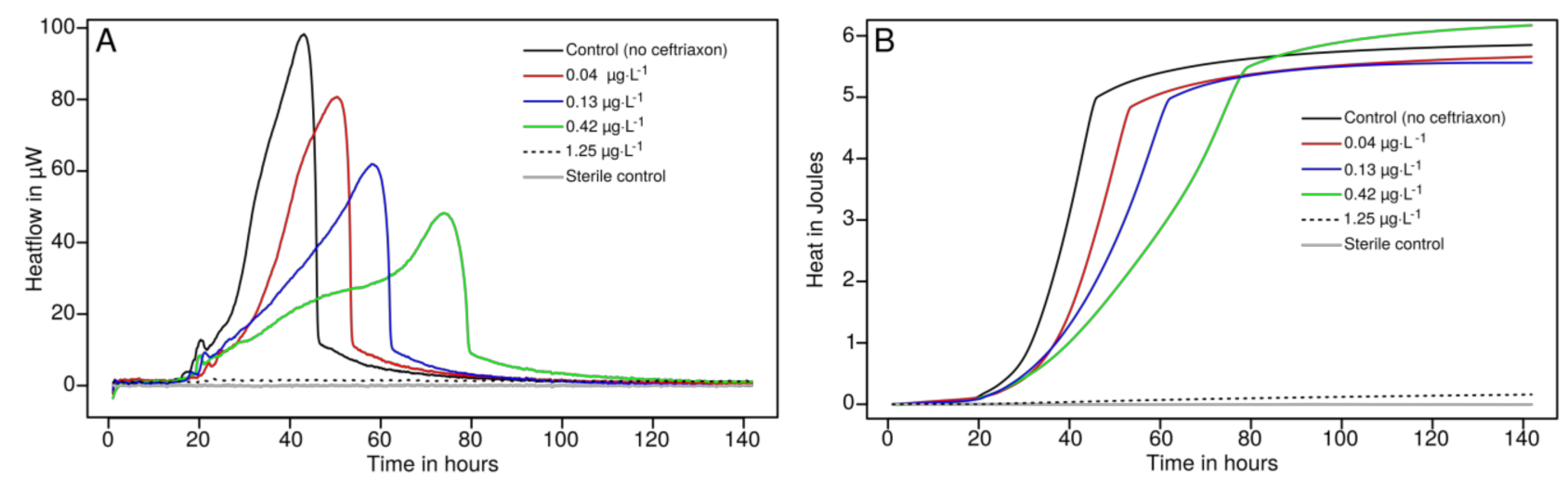

Figure 2. Heatflow (A) and heat over time (B) during the growth of N. gonorrhoea ATCC 43069 exposed to increasing concentrations of ceftriaxone.

\section{Discussion}

Overall, the use of the IMC is easier than culturing, and there is little preparation time. There is also the possibility of measuring antimicrobial susceptibility and rapidly discriminating between susceptible and resistant strains. Once an optimal medium has been chosen, detection is rather simple. In the development of calorimetric methods for the detection of this fastidious pathogens, other media such as Thayer-Martin agar or modified chocolate agar could be of interest [43]. However, in this study we focused on the use of liquid media as they are more suited for a practical use considering diagnostic applications and calorimetry. Still, the above-mentioned agar media could be of interest in the study of the formation of biofilm as these structures have been shown to form on epithelial cells and cervical cells during Neisseria infections [44]. In addition, future studies should also include the use of selective antimicrobial supplements for the direct isolation of Neisseria species [43].

The detection of $N$. gonorrhoea using isothermal microcalorimetry is slower than with NAAT, but it allows more evaluations once the IMC measurements are completed. Indeed, since the sealed ampoule still contains almost undisturbed sample with higher amounts of Neisseria, those bacteria can be recovered for additional identification or confirmation using MALDI-TOF or serological testing, for example. This is not possible with many NAAT-based techniques at this point but is still required as NAAT can be sensitive to other non-pathogenic but closely related Neisseria species [16,17,19].

In addition, we must emphasize that this study is very preliminary work and that many improvements are possible when considering the nature and composition of the medium. Indeed, as with non-motile microbial cells, hemoglobin (provided as dried red blood cells) and starch (insoluble) tend to sediment and are found at the bottom of the vial after the experiment. Therefore, it is very likely that the conditions for the growth of $N$. gonorrhoea are not homogenous throughout the vial and thus might not be optimal. Previous studies have shown that the use of Percoll or Ficoll that increase the density of the medium is a good solution to avoid such sedimentation, thus providing much more homogenous conditions for growth [45]. This; however, was not in the scope of the present study but will be considered and further investigated using similar media. There are also many other supplements such as Vitox or Yeast autolysate that could be used to make the 
growth of N. gonorrhoea and other Neisseria species faster. This is indeed of interest as IMC has been used for a long time to optimize growth condition for industrial purposes but also for human cell research [46-48]. Finally, we did not investigate selective supplements for direct determination and isolation from urine samples or swabs. This will also become of interest as the technique progresses.

With respect to antimicrobial susceptibility testing, our results show that with rather low concentration susceptibility could be determined within $12 \mathrm{~h}$. At this point isolation would be needed before running a calorimetry measurement. As isolation takes $24 \mathrm{~h}$ and testing takes another $12 \mathrm{~h}$, results can be expected within $36 \mathrm{~h}$. Overall this is still $12 \mathrm{~h}$ faster than conventional methods $[49,50]$. Use of a higher initial inoculum is expected to speed up the detection, and we estimate that with an inoculum of $10^{6} \mathrm{CFU} \cdot \mathrm{mL}^{-1}$ the time to results could be lowered to $28 \mathrm{~h}$. This would be similar to drug susceptibility testing using direct qPCR [51]. Finally, using additional preparation steps such as magnetic antibodies, it might be possible to skip the initial isolation, as a high amount of Neisseria would likely outgrow other microbes (if any) present after the purification step.

In conclusion, the use of isothermal microcalorimetry provides an interesting and useful tool to investigate fastidious microbes that require media incompatible with optical detection conventionally used in many commercial systems. Detection and drug susceptibility testing of $N$. gonorrhoea was rapidly performed. Further optimization with respect to the microbial culture condition will surely further decrease the time to detection and the time required for drug susceptibility testing. Therefore, we expect isothermal microcalorimetry to become a valuable tool for diagnostics and research of so-called fastidious microorganisms, including N. gonorrhoea.

Author Contributions: Conceptualization, O.B. and G.B.; methodology, O.B.; formal analysis, A.E.G., T.L., O.B.; original draft preparation, A.E.G., T.L., A.P.S., M.M., O.B. and G.B. All authors have read and agreed to the published version of the manuscript.

Funding: This research received no external funding. O.B. is supported by the Merian Iselin Stiftung.

Institutional Review Board Statement: The study was conducted according to the guidelines of the Declaration of Helsinki.

Informed Consent Statement: Informed consent was obtained from all subjects involved in the study.

Data Availability Statement: Data presented in this study are available on request from the corresponding author.

Conflicts of Interest: The authors declare no conflict of interest.

\section{References}

1. Rowley, J.; Hoorn, S.V.; Korenromp, E.; Low, N.; Unemo, M.; Abu-Raddad, L.J.; Chico, R.M.; Smolak, A.; Newman, L.; Gottlieb, S.; et al. Chlamydia, gonorrhoea, trichomoniasis and syphilis: Global prevalence and incidence estimates, 2016. Bull. World Health Organ. 2019, 97, 548. [CrossRef]

2. Rubin, D.H.F.; Ross, J.D.C.; Grad, Y.H. The frontiers of addressing antibiotic resistance in Neisseria gonorrhoeae. Transl. Res. 2020, 220, 122-137. [CrossRef] [PubMed]

3. Unemo, M.; Seifert, H.S.; Hook, E.W.; Hawkes, S.; Ndowa, F.; Dillon, J.-A.R. Gonorrhoea. Nat. Rev. Dis. Prim. 2019, 5, 79. [CrossRef] [PubMed]

4. Hook, E.W.; Bernstein, K. Kissing, saliva exchange, and transmission of Neisseria gonorrhoeae. Lancet Infect. Dis. 2019, 19, e367-e369. [CrossRef]

5. Elias, J.; Frosch, M.; Vogel, U. Neisseria. In Manual of Clinical Microbiology; Wiley Online Library: Hoboken, NJ, USA, 2015; pp. 635-651.

6. Noble, R.C.; Cooper, R.M.; Miller, B.R. Pharyngeal colonisation by Neisseria gonorrhoeae and Neisseria meningitidis in black and white patients attending a venereal disease clinic. Sex. Transm. Infect. 1979, 55, 14-19. [CrossRef]

7. Danby, C.S.; Cosentino, L.A.; Rabe, L.K.; Priest, C.L.; Damare, K.C.; Macio, I.S.; Meyn, L.A.; Wiesenfeld, H.C.; Hillier, S.L. Patterns of Extragenital Chlamydia and Gonorrhea in Women and Men Who Have Sex with Men Reporting a History of Receptive Anal Intercourse. Sex. Transm. Dis. 2016, 43, 105-109. [CrossRef] [PubMed] 
8. Hook, E.W.; Judson, F.N.; Handsfield, H.H.; Ehret, J.M.; Holmes, K.K.; Knapp, J.S. Auxotype/serovar diversity and antimicrobial resistance of neisseria gonorrhoeae in two mid-sized american cities. Sex. Transm. Dis. 1987, 14, 141-146. [CrossRef] [PubMed]

9. Brunham, R.C.; Gottlieb, S.L.; Paavonen, J. Pelvic Inflammatory Disease. N. Engl. J. Med. 2015, 372, 2039-2048. [CrossRef] [PubMed]

10. Bonkat, G.; Pickard, R.; Bartoletti, R.; Cai, T.; Bruyere, F.; Geerlings, S.E.; Köves, B.; Wagenlehne, F.; Pilatz, A.; Pradere, B.; et al. EAU Guidelines on Urological Infections; European Association of Urology: Arnhem, The Netherlands, 2019.

11. Barbee, L.A.; Golden, M.R. Aztreonam for Neisseria gonorrhoeae: A systematic review and meta-analysis. J. Antimicrob. Chemother. 2020, 75, 1685-1688. [CrossRef] [PubMed]

12. Meyer, T.; Buder, S. The laboratory diagnosis of neisseria gonorrhoeae: Current testing and future demands. Pathogens $2020,9,91$. [CrossRef] [PubMed]

13. Bignell, C.; Unemo, M. 2012 European guideline on the diagnosis and treatment of gonorrhoea in adults. Int. J. STD AIDS 2013, 24, 85-92. [CrossRef]

14. Bachmann, L.H.; Johnson, R.E.; Cheng, H.; Markowitz, L.; Papp, J.R.; Palella, F.J.; Hook, E.W. Nucleic acid amplification tests for diagnosis of Neisseria gonorrhoeae and Chlamydia trachomatis rectal infections. J. Clin. Microbiol. 2010, 48, 1827-1832. [CrossRef] [PubMed]

15. Bachmann, L.H.; Johnson, R.E.; Cheng, H.; Markowitz, L.E.; Papp, J.R.; Edward, I.W.H. Nucleic acid amplification tests for diagnosis of Neisseria gonorrhoeae oropharyngeal infections. J. Clin. Microbiol. 2009, 47, 902-907. [CrossRef]

16. Palmer, H.M.; Mallinson, H.; Wood, R.L.; Herring, A.J. Evaluation of the specificities of five DNA amplification methods for the detection of Neisseria gonorrhoeae. J. Clin. Microbiol. 2003, 41, 835-837. [CrossRef]

17. Tabrizi, S.N.; Unemo, M.; Limnios, A.E.; Hogan, T.R.; Hjelmevoll, S.O.; Garland, S.M.; Tapsall, J. Evaluation of six commercial nucleic acid amplification tests for detection of Neisseria gonorrhoeae and other Neisseria species. J. Clin. Microbiol. 2011, 49, 3610-3615. [CrossRef]

18. Tabrizi, S.N.; Unemo, M.; Golparian, D.; Twin, J.; Limnios, A.E.; Lahra, M.; Guy, R. Analytical evaluation of GeneXpert CT/NG, the first genetic point-of-care assay for simultaneous detection of Neisseria gonorrhoeae and Chlamydia trachomatis. J. Clin. Microbiol. 2013, 51, 1945-1947. [CrossRef]

19. Humbert, M.V.; Christodoulides, M. Atypical, yet not infrequent, infections with neisseria species. Pathogens 2020, 9, 10. [CrossRef]

20. Cheng, A.; Kirby, J.E. Evaluation of the hologic gen-probe PANTHER, APTIMA combo 2 assay in a tertiary care teaching hospital. Am. J. Clin. Pathol. 2014, 141, 397-403. [CrossRef]

21. Van Der Pol, B.; Williams, J.A.; Fuller, D.A.; Taylor, S.N.; Hook, E.W. Combined testing for chlamydia, gonorrhea, and trichomonas by use of the BD max CT/GC/TV assay with genitourinary specimen types. J. Clin. Microbiol. 2017, 55, 155-164. [CrossRef] [PubMed]

22. Serra-Pladevall, J.; Caballero, E.; Roig, G.; Juvé, R.; Barbera, M.J.; Andreu, A. Comparison between conventional culture and NAATs for the microbiological diagnosis in gonococcal infection. Diagn. Microbiol. Infect. Dis. 2015, 83, 341-343. [CrossRef] [PubMed]

23. Braissant, O.; Wirz, D.; Göpfert, B.; Daniels, A.U. Biomedical use of isothermal microcalorimeters. Sensors 2010, 10, 9369-9383. [CrossRef] [PubMed]

24. Braissant, O.; Wirz, D.; Göpfert, B.; Daniels, A.U. Use of isothermal microcalorimetry to monitor microbial activities. FEMS Microbiol. Lett. 2010, 303, 1-8. [CrossRef]

25. Vasala, A.; Hytönen, V.P.; Laitinen, O.H. Modern Tools for Rapid Diagnostics of Antimicrobial Resistance. Front. Cell. Infect. Microbiol. 2020, 10, 308. [CrossRef]

26. Nykyri, J.; Herrmann, A.M.; Håkansson, S. Isothermal microcalorimetry for thermal viable count of microorganisms in pure cultures and stabilized formulations. BMC Microbiol. 2019, 19, 65. [CrossRef]

27. Braissant, O.; Astasov-Frauenhoffer, M.; Waltimo, T.; Bonkat, G. A review of methods to determine viability, vitality, and metabolic rates in microbiology. Front. Microbiol 2020, 11, 547458. [CrossRef] [PubMed]

28. Bonkat, G.; Braissant, O.; Widmer, A.F.; Frei, R.; Rieken, M.; Wyler, S.; Gasser, T.C.; Wirz, D.; Daniels, A.U.; Bachmann, A. Rapid detection of urinary tract pathogens using microcalorimetry: Principle, technique and first results. BJU Int. 2012, 110, 892-897. [CrossRef] [PubMed]

29. Braissant, O.; Müller, G.; Egli, A.; Widmer, A.; Frei, R.; Halla, A.; Wirz, D.; Gasser, T.C.; Bachmann, A.; Wagenlehner, F.; et al. Seven hours to adequate antimicrobial therapy in urosepsis using isothermal microcalorimetry. J. Clin. Microbiol. 2014, 52, 624-626. [CrossRef]

30. Baldoni, D.; Hermann, H.; Frei, R.; Trampuz, A.; Steinhuber, A. Performance of microcalorimetry for early detection of methicillin resistance in clinical isolates of Staphylococcus aureus. J. Clin. Microbiol. 2009, 47, 774-776. [CrossRef] [PubMed]

31. Furustrand Tafin, U.; Orasch, C.; Trampuz, A. Activity of antifungal combinations against Aspergillus species evaluated by isothermal microcalorimetry. Diagn. Microbiol. Infect. Dis. 2013, 77, 31-36. [CrossRef] [PubMed]

32. Boillat-Blanco, N.; Furustrand Tafin, U.; Jaton, K.; Trampuz, A. Susceptibility testing of Mycobacterium abscessus by isothermal microcalorimetry. Diagn. Microbiol. Infect. Dis. 2015, 83, 139-143. [CrossRef] [PubMed]

33. Von Ah, U.; Wirz, D.; Daniels, A. Isothermal micro calorimetry a new method for MIC determinations: Results for 12 antibiotics and reference strains of E. coli and S. aureus. BMC Microbiol. 2009, 9, 106. [CrossRef] [PubMed] 
34. Howell, M.; Wirz, D.; Daniels, A.U.; Braissant, O. Application of a microcalorimetric method for determining drug susceptibility in Mycobacterium species. J. Clin. Microbiol. 2012, 50, 16-20. [CrossRef]

35. Rodríguez, D.; Daniels, A.U.; Urrusti, J.L.; Wirz, D.; Braissant, O. Evaluation of a low-cost calorimetric approach for rapid detection of tuberculosis and other mycobacteria in culture. J. Appl. Microbiol. 2011, 111, 1016-1024. [CrossRef]

36. Battley, E.H. Absorbed heat and heat of formation of dried microbial biomassstudies on the thermodynamics of microbial growth J. Therm. Anal. Calorim. 2003, 74, 709-721. [CrossRef]

37. Braissant, O.; Bonkat, G.; Wirz, D.; Bachmann, A. Microbial growth and isothermal microcalorimetry: Growth models and their application to microcalorimetric data. Thermochim. Acta 2013, 555, 64-71. [CrossRef]

38. Zwietering, M.H.; Jongenburger, I.; Rombouts, F.M.; Van't Riet, K. Modeling of the bacterial growth curve. Appl. Environ. Microbiol. 1990, 56, 1875-1881. [CrossRef] [PubMed]

39. Kahm, M.; Hasenbrink, G.; Lichtenberg-Fraté, H.; Ludwig, J.; Kschischo, M. grofit: Fitting Biological Growth Curves with R. J. Stat. Softw. 2010, 33. [CrossRef]

40. Braissant, O.; Bachmann, A.; Bonkat, G. Microcalorimetric assays for measuring cell growth and metabolic activity: Methodology and applications. Methods 2015, 76, 27-34. [CrossRef]

41. Braissant, O.; Bonkat, G.; Bachmann, A. Isothermal Microcalorimetry for the Investigation of Clinical Samples: Past and Present. In Biocalorimetry; CRC Press: Boca Raton, FL, USA, 2016.

42. Maskow, T.; Paufler, S. What does calorimetry and thermodynamics of living cells tell us? Methods 2015, 76, 3-10. [CrossRef] [PubMed]

43. Atlas, R.M. Handbook of Microbiological Media; CRC Press: Boca Raton, FL, USA, 2004; ISBN 0429129033.

44. Greiner, L.L.; Edwards, J.L.; Shao, J.; Rabinak, C.; Entz, D.; Apicella, M.A. Biofilm formation by Neisseria gonorrhoeae. Infect. Immun. 2005, 73, 1964-1970. [CrossRef] [PubMed]

45. Maskow, T.; Morais, F.M.; Rosa, L.F.M.; Qian, Y.G.; Harnisch, F. Insufficient oxygen diffusion leads to distortions of microbial growth parameters assessed by isothermal microcalorimetry. RSC Adv. 2014, 4, 32730-32737. [CrossRef]

46. Kemp, R.B.; Guan, Y.H. The application of heat flux measurements to improve the growth of mammalian cells in culture. Thermochim. Acta 2000, 349, 23-30. [CrossRef]

47. Sivaprakasam, S.; Schuler, M.M.; Hama, A.; Hughes, K.M.; Marison, I.W. Biocalorimetry as a process analytical technology process analyser; Robust in-line monitoring and control of aerobic fed-batch cultures of crabtree-negative yeast cells. J. Therm. Anal. Calorim. 2011, 104, 75-85. [CrossRef]

48. Schuler, M.M.; Sivaprakasam, S.; Freeland, B.; Hama, A.; Hughes, K.M.; Marison, I.W. Investigation of the potential of biocalorimetry as a process analytical technology (PAT) tool for monitoring and control of Crabtree-negative yeast cultures. Appl. Microbiol. Biotechnol. 2012, 93, 575-584. [CrossRef] [PubMed]

49. Putnam, S.D.; Lavin, B.S.; Stone, J.R.; Oldfield, E.C.; Hooper, D.G. Evaluation of the standardized disk diffusion and agar dilution antibiotic susceptibility test methods by using strains of Neisseria gonorrhoeae from the United States and Southeast Asia. J. Clin. Microbiol. 1992, 30, 974-980. [CrossRef] [PubMed]

50. Sabour, S. Etest to detect drug-resistant neisseria gonorrhoeae to contemporary treatment; methodological issues concerning accuracy and reproducibility. J. Med. Microbiol. 2018, 67, 465. [CrossRef]

51. Chen, L.; Shin, D.J.; Zheng, S.; Melendez, J.H.; Gaydos, C.A.; Wang, T.H. Direct-qPCR Assay for Coupled Identification and Antimicrobial Susceptibility Testing of Neisseria gonorrhoeae. ACS Infect. Dis. 2018, 4, 1377-1384. [CrossRef] [PubMed] 